\title{
然 \\ A NOVA DINÂMICA LOCAL NA COMUNICAÇÃO LEGISLATIVA: UM OLHAR SOBRE O PERFIL DAS TVS CÂMARAS MUNICIPAIS DO INTERIOR DO ESTADO DE SÃO PAULO
}

\author{
THE NEW LOCAL LEGISLATIVE COMMUNICATION DYNAMIC: A LOOK AT \\ THE PROFILE OF CITY COUNSIL TVS FROM SÃO PAULO STATE INTERIOR
}

\section{LA NUEVA DINÁMICA LOCAL EN LA COMUNICACIÓN LEGISLATIVA: UNA MIRADA SOBRE LOS PERFILES DE LAS TVS CÁMARAS MUNICIPALES DEL INTERIOR DEL ESTADO DE SÃO PAULO}

\author{
Maria Carolina Silva Rocha Vieira ${ }^{1}$ \\ Maximiliano Martin Vicente ${ }^{2}$
}

\begin{abstract}
Resumo: Com a criação da Rede Legislativa de TV, em 2012, as emissoras ligadas aos Poderes Legislativos federais, estaduais e municipais, antes com atuação dispersa, passam a ter a chance de se tornar um bloco mais coeso. Baseada na multiprogramação e na divisão de responsabilidades, a nova configuração da Rede traz ainda um inédito protagonismo ao cenário local. Por meio de revisão bibliográfica, levantamento de dados oficiais e entrevistas com gestores, este artigo lança um olhar às TVs Câmaras municipais (do interior do estado de São Paulo, onde hoje há a maior concentração destas), investigando se nelas residem possibilidades para uma comunicação legislativa local que não só trabalhe com o conceito de transparência, mas também com a promoção de cidadania e aproximação da sociedade às esferas de tomadas de decisões.
\end{abstract}

Palavra-chave: Comunicação Legislativa; Comunicação Pública; TV Legislativa; TV Câmara Municipal; Radiodifusão Brasileira.

Abstract: With the beginning of "Rede Legislativa de TV" in 2012, the Federal, State and Local Legislative
TVs channels had the chance to become a more cohesive group and not act in a spread way anymore. Based
in the multiprogramming feature and sharing responsibilities, its new configuration brings also an
unprecedented protagonism to the local broadcast scenario. This article uses bibliography review, data
research and interview techniques to put light on City Council TVs from the São Paulo State interior, where
today there are more of this type of broadcasters in Brazil. The goal is to investigate if there are possibilities,
in these channels, for a local legislative communication which not only would work with transparency, but
also with promotion of active citizenship and approximation of the society to the decision making spheres.

Keywords: Legislative Communication; Public Communication; Legislative TV; City Counsil TV; Brazilian Broadcast.

Resumen: Con la creación de la "Rede Legislativa de TV", en 2012, las emisoras ligadas a los Poderes Legislativos federales, estaduales y municipales, antes con actuación dispersa, pasan a tener la oportunidad de tornarse un bloco más cohesivo. Basada en la multiprogramación y en la división de las responsabilidades, la nueva configuración de la Red trae un inédito protagonismo al escenario local. Utilizando revisión bibliográfica, levantamiento de datos y entrevistas con gestores, este artículo pone una mirada en las TVs Cámaras Municipales (del interior del estado de São Paulo, onde hoy están más

\footnotetext{
${ }^{1}$ Doutoranda no Programa de Pós-graduação em Comunicação da Faculdade de Arquitetura, Artes e Comunicação da Universidade Estadual Paulista (UNESP) e repórter legislativa na Câmara Municipal de Botucatu - SP. Orcid: https://orcid.org/0000-0003-0232-9515. E-mail: mcarol.srvieira@gmail.com

2 Professor-doutor do Programa de Pós-graduação em Comunicação da Faculdade de Arquitetura, Artes e Comunicação da Universidade Estadual Paulista (FAAC/Unesp). E-mail: mm.vicente@ unesp.br
} 
concentradas), investigando si en ellas existen posibilidades para una comunicación legislativa local que no solo trabaje con transparencia, pero también con la promoción de la ciudadanía y la aproximación de la sociedad a las esferas de tomadas de decisión.

Palabras clave: Comunicación Legislativa; Comunicación Pública; TV Legislativa; TV Câmara Municipal; Radiodifusión Brasileña.

\section{Introdução}

Este artigo é fruto de um passo inicial no processo geral de uma pesquisa de doutorado que pretende estudar o potencial exercício de comunicação cidadã no contexto de uma nova comunicação legislativa, que não só coloca as TVs Câmaras como veículos em evidência, mas também traz um inédito protagonismo ao cenário local/municipal. Este primeiro passo consiste em levantar dados e traçar o perfil das dezesseis TVs Câmaras municipais do interior do estado de São Paulo já pertencentes à Rede Legislativa de TV Digital - que são o corpus definido de pesquisa, por motivos explicados ao longo do texto - a fim de iniciar uma discussão sobre seu papel e sobre a atual configuração da modalidade de radiodifusão pública/estatal da qual fazem parte. Para isso, o artigo foi dividido em três tópicos que trazem uma breve revisão bibliográfica sobre o caminho percorrido pelas TVs Legislativas até aqui, seguidos pela parte empírica do trabalho, que faz uma análise das informações levantadas sobre as TVs estudadas para a pesquisa em desenvolvimento.

\section{Estado brasileiro como agente comunicador}

A existência das TVs legislativas se deve muito à vontade do parlamento de se comunicar com a sociedade, tornando sua imagem mais positiva e próxima do cidadão. Desde seu início, é possível perceber um duplo objetivo, de "tanto aproximar a população das discussões que ocorrem nas Câmaras [...] permitindo aumentar o controle dos cidadãos sobre essas instituições e ampliar a participação popular no processo legislativo" (LEMOS; BERNARDES; BARROS, 2011, p. 2) quanto de tentar revigorar a própria imagem sem depender das mídias comerciais. Embora hoje tais emissoras sejam uma parcela significativa da comunicação que parte do setor público e terem sido, após a redemocratização, grandes protagonistas no processo de criar transparência e visibilidade política ao setor (BARROS; LEMOS, 2019, p. 109), elas estão longe de representar a primeira e única iniciativa do Estado brasileiro em se colocar não só como regulador da comunicação, mas também como agente comunicador.

Carvalho (2014), em sua tese de doutorado sobre a função e a legitimação das TVs Legislativas federais, lembra que a radiodifusão é um serviço que o Estado não pode permitir que seja feito exclusivamente por terceiros. Devido ao artigo 223 da Constituição Federal, que exige por parte do Estado a observância na radiodifusão ao "princípio da complementaridade dos sistemas de radiodifusão privado, público e estatal" (BRASIL, 1988, s/p), ele tem o dever de não só conceder, mas também prestar esse serviço. O princípio veio oficializar a ideia de que esses 
sistemas não são concorrentes e sim complementares, abrindo portas para que busquem atuações específicas. A mídia estatal, por exemplo, teria o papel de "ser institucional e de prestar um serviço público de acesso à informação [...] a partir de uma credibilidade baseada não apenas na objetividade, mas no caráter formativo ou informativo da prestação de contas à sociedade" (CARVALHO, 2014, p. 64).

Enquanto a Constituição de 1988 colocou certa visibilidade normativa à radiodifusão pública/estatal, em especial em seu capítulo V sobre a Comunicação Social (BRASIL, 1988, s/p) na prática, o movimento de criar canais de comunicação públicos sem mediação privada vem de muito antes no Brasil. Segundo Barros:

\footnotetext{
A tentativa do poder político de manter um canal direto de comunicação com a população que não passe pelos filtros dos veículos privados é antiga. Desde 1935, o governo federal mantém o programa A Voz do Brasil, antes conhecido como Hora do Brasil, instituído pelo governo Getúlio Vargas, e que tenta fazer essa ponte sem mediações entre as ações governamentais e os cidadãos. Poderíamos ir mais longe e dizer que a imprensa no Brasil nasceu oficial. O primeiro jornal impresso em solo brasileiro, ainda no período colonial, "A Gazeta do Rio de Janeiro", trazia notícias que eram basicamente comunicados do governo. (BARROS, 2007, p. 3).
}

A Voz do Brasil, primeiro programa radiofônico que parte do Estado a dedicar espaço a notícias do Poder Legislativo, também é apontado por Eugênio Bucci como iniciativa chave para se entender a própria comunicação pública no Brasil. Segundo ele, é no noticiário obrigatório "chapa-branca" que "mora a gênese das fórmulas pelas quais o equipamento público é posto a serviço da vaidade particular dos que mandam" (BUCCI, 2015, p. 138), levantando a discussão sempre atual sobre qual é a comunicação pública ideal e qual é a que se exerce de fato por uma estrutura estatal denominada por ele de Estado de Narciso.

Aqui, o importante é entender que a tentativa do Estado de se aproximar da população por meio do exercício da comunicação pública não é nova no âmbito federal, vindo carregada de pontos que ultrapassam a mera prestação de contas à sociedade. No caso do Legislativo como agente comunicador, pode-se notar questões desde a intenção de melhorar a imagem do Parlamento perante a população e criar um canal de diálogo alternativo às mídias comerciais até o indesejado uso dos recursos públicos com finalidades não-públicas, dilemas que refletem na prática e na estrutura ainda em formação das TVs Legislativas hoje.

\section{As TVs Legislativas na complementariedade do sistema de radiodifusão}

Após a Constituição de 1988 estabelecer que o sistema de radiodifusão deveria manter um equilíbrio entre emissoras públicas, privadas e estatais, o marco para o surgimento e consolidação das TVs Legislativas foi a aprovação da Lei da Cabodifusão. A Lei 8.977 de 1995 veio para regulamentar o serviço das operadoras comerciais de serviço à cabo no Brasil, porém acabou tendo um papel fundamental para a expansão das emissoras públicas/estatais no país. A 
lei passou a obrigar tais operadoras a destinarem canais básicos de utilização gratuita a certos setores, entre eles ao legislativo municipal (compartilhando o canal com a Assembleia de respectivo estado); à Câmara dos Deputados e ao Senado Federal. Recebendo, logo de início, um "DNA público e não apenas institucional” (PAULINO, 2019, p. 24), as TVs Legislativas nasceram no sistema a cabo graças ao que Letícia Renault chama de artigo inovador, pois:

Pela primeira vez, a legislação brasileira de radiodifusão determinou que, para operar um negócio privado, seria preciso contemplar simultaneamente, sem interrupção e por período indeterminado, a programação gerada por outras fontes que não as redes privadas ou a rede pública existente. (RENAULT, 2004, p. 40).

Com o direito de transmissão garantido, o Poder Legislativo começou a ocupar este espaço de forma não organizada e por iniciativas isoladas de cada Parlamento, Assembleia ou Câmara: em 1995, entrava no ar a TV Assembleia de Minas Gerais, em 1996 a TV Senado e em 1998 era a vez da TV Câmara Federal. Na esfera municipal, a TV Câmara Bauru foi uma das primeiras, iniciando seus trabalhos também em 1998. A partir daí, "pipocaram” TVs Assembleias e TVs Câmaras pelo país, cada uma a sua maneira. A formação dispersa desta modalidade de comunicação do Poder Legislativo é uma característica relevante do setor, uma vez que reflete a falta de normativa que a rege. Até hoje, embora discussões acadêmicas e profissionais sobre o assunto busquem trazer parâmetros mínimos à sua atuação, a única real referência normativa que recai sobre as emissoras legislativas é a Lei do Cabo, que determina que devem se voltar "para a documentação dos trabalhos parlamentares, especialmente a transmissão ao vivo das sessões" (Lei 8.977, de 6 de janeiro de 1995).

Enquanto a não-uniformidade das emissoras legislativas pode propiciar certa riqueza de experiências, ao mesmo tempo causa efeitos colaterais como a dificuldade em enxergar onde elas estão no sistema complementar de radiodifusão brasileiro. Em uma análise fria do caso, estes canais seriam estritamente estatais, corroborando para a classificação o cumprimento de três requisitos básicos a emissoras estatais propostos por Bucci; Fiorini; Chiaretti (2012) em um relatório da UNESCO:

Sua propriedade e sua natureza jurídica a vinculam direta ou indiretamente ao
Estado, nos termos da legislação que rege a administração pública do país; sua
gestão cotidiana está subordinada a autoridades de um dos três poderes da
República; e sua programação sofre limites decorrentes dos dois requisitos
anteriores, estando mais a serviço das necessidades de divulgação decorrentes
da lógica interna do Estado do que a serviço de refletir livremente o debate e a
diversidade cultural que resulta das dinâmicas não-estatais típicas da vida
social. (BUCCI; FIORINI; CHIARETTI, 2012, p. 21).

No entanto, para além dos requisitos básicos e do cumprimento legal das transmissões ao vivo das atividades em plenário, as práticas e as estruturas das TVs Legislativas permanecem diversificadas. Sant'Anna (2019), estudioso da comunicação legislativa que cunhou para ela o 
A nova dinâmica local na comunicação legislativa: um olhar sobre o perfil das TVs Câmaras municipais do interior do estado de São Paulo

termo "mídia das fontes", aponta inclusive a atual falta de regramento e a importância de se elaborar um marco legislativo para o setor, já que sem ele a citada diversidade pode facilmente se transformar negativamente em desvio de função. Diante disso, abre-se certa margem de interpretação para como devem funcionar e para que, afinal, servem afora prestar contas do Poder Legislativo. Carvalho (2014), por exemplo, as classifica como públicas, estatais e institucionais, não vendo contradições na tripla definição desde que haja um equilíbrio mínimo entre as dimensões. Enquanto o tópico segue em discussão, mais um passo foi dado na jornada das TVs Legislativas em 2012, com grande impacto ao protagonismo local da categoria.

\section{A Rede Legislativa de Rádio e TV e o novo protagonismo local}

Até então dispersas pelo país, com poucas iniciativas que atuavam como aglutinadoras do setor - é o caso da ASTRAL, Associação Brasileira de Televisões e Rádios Legislativas, inaugurada em 2002 com o intuito de representar o interesse das atividades de comunicação das casas legislativas, entre outros propósitos - as emissoras legislativas começam a demonstrar maior coesão a partir do Ato da Mesa n 52, de 17 de outubro de 2012, que cria a Rede Legislativa de TV Digital e a Rede Legislativa de Rádio da Câmara dos Deputados.

Com a implantação do sistema digital de televisão no país, a Rede tornaria possível a expansão territorial das TVs Legislativas e, finalmente, sua entrada na rede aberta, universalizando o acesso às suas programações. Além de ser "a primeira rede de televisão a se formar no Brasil com o recurso digital da multiprogramação, que possibilita o uso de um mesmo transmissor para quatro emissoras independentes" (BRASIL, 2020, n.p.), a Rede trabalharia seu crescimento por meio de uma até então incomum cooperação entre TV Câmara federal, TV Senado, TV Assembleia estadual e TV Câmara municipal, uma vez que "a Câmara e o Senado compartilham seus canais com os parceiros e dividem custos e responsabilidades" (BRASIL, 2020, n.p.).

Na prática, com o recurso da multiprogramação um mesmo canal pode ser dividido entre quatro emissoras da União. Por meio de acordos de cooperação técnica entre Câmara dos Deputados, Senado, Assembleias e Câmaras municipais, a tarefa de expandir o sinal de televisão aos municípios brasileiros fica dividida: o Poder Legislativo federal concede o canal, dá suporte ao seu processo de implantação e de maneira geral gerencia a Rede, enquanto o Poder Legislativo municipal arca com os custos da recepção e da transmissão do sinal de TV digital. Nas capitais, os custos são repartidos entre Câmara dos Deputados e assembleia estadual.

Para que uma Câmara municipal e a população referente a ela contem com uma TV Legislativa, a primeira etapa necessária é que esta demonstre interesse em firmar acordo para implantação da Rede Legislativa no município. Ou seja, não só o surgimento de novos canais legislativos municipais, mas também a amplificação do acesso aos canais legislativos federais e estaduais já existentes dependem primeiramente do interesse do Poder Legislativo local em fazer 
tal investimento. Dessa forma, a configuração baseada no compartilhamento de canais e de responsabilidades da Rede acabou por provocar um inédito protagonismo do local.

Ao lado de debates sobre a própria organização da Rede Legislativa, o ineditismo posiciona no cerne da matéria as potencialidades cidadãs que a comunicação legislativa local pode começar a desenhar (ou já vem desenhando). Heloisa Matos, que tem diversas publicações sobre comunicação pública e algumas, especificamente, sobre comunicação legislativa, defende que esta, "para realizar-se plenamente, necessita de uma relação íntima com a prática da cidadania" (MATOS, 1999, p. 9), devendo pautar-se pela "formação de atitudes cidadãs, participativas e conscientes" (MATOS, 1999, p. 9). Ela chega a defender que para divulgação de informação cidadã, é preciso espaços adequados para debates e trocas de ideia e que esse conceito tem se expressado melhor no âmbito da municipalidade, já que é propícia "ao entendimento da comunicação pública como meio de renovação de práticas democráticas relacionadas à vivência direta de problemas e à busca de soluções” (MATOS, 2009, p. 6). Cicília Peruzzo, em artigo sobre mídia regional e local, também afirma sobre emissoras legislativas municipais que "embora haja distorções (mal uso de alguns destes canais), os propósitos globais da programação não deixam de ser legal e eticamente educativo-culturais, de desenvolvimento comunitário e em prol da cidadania" (PERUZZO, 2005, p. 83). Segundo ela, não se deve menosprezar a força do local quanto fonte de informação.

De fato, este artigo não pretende ignorar o novo cenário e a discussão que este sugere, uma vez que os números referentes às TVs Legislativas tendem a ser cada vez mais expressivos. Com dados atualizados em fevereiro de 2020 (BRASIL, 2020), são 37 as cidades que contam com TVs Câmaras inseridas na Rede Legislativa de TV e que, portanto, estão no ar na rede aberta de televisão. Assim, hoje, na Rede, as TVs Câmaras municipais já ultrapassaram em número as TVs de nível federal (TV Câmara e TV Senado) e as TVs de nível estadual (as TVs Assembleias que estão no ar nos estados de Acre, Amazônia, Amapá, Bahia, Ceará, Espírito Santo, Goiás, Maranhão, Minas Gerais, Mato Grosso, Pará, Paraíba, Pernambuco, Rio de Janeiro, Rio Grande do Norte, Roraima, Rio Grande do Sul, Santa Catarina, Sergipe, São Paulo e Tocantins). A tendência ainda é de aumento na diferença numérica nos próximos anos, uma vez que o Brasil possui muito mais municípios do que estados (5.570 municípios versus 26 estados federados), o que limita o crescimento das TVs Assembleias e impulsiona o das TVs Câmaras - atualmente, por exemplo, além das 37 cidades no ar da Rede Legislativa de Rádio e TV, 117 estão em fase de implantação e outras 365 aguardam a liberação de um canal pela Câmara dos Deputados.

O maior número de cidades que já contam com TVs Câmaras na rede aberta de televisão se encontra no estado de São Paulo, especificamente em seu interior. Por esse motivo, elas foram escolhidas como corpus de pesquisa ${ }^{3}$, o qual será analisado a seguir.

\footnotetext{
${ }^{3}$ A TV Câmara SP, veículo da Câmara Municipal da cidade de São Paulo, foi excluída do corpus de pesquisa, pois diz
} 
A nova dinâmica local na comunicação legislativa: um olhar sobre o perfil das TVs Câmaras municipais do interior do estado de São Paulo

\section{Perfil das TVs Câmaras municipais do interior do estado de São Paulo}

Até o início de 2020, a Rede Legislativa de Rádio e TV havia chegado a 16 cidades do interior de São Paulo. São elas: Assis, Barretos, Bauru, Botucatu, Campinas, Franca, Jacareí, Jaú, Jundiaí, Marília, Mogi das Cruzes, Piracicaba, Ribeirão Preto, São José do Rio Preto, Sorocaba e Tupã. Para um olhar inicial que permitisse traçar um perfil destas emissoras, foi feito um levantamento de dados referentes aos canais, aos modelos de organização de gestão e de equipe técnica, e ao caráter do conteúdo que forma a programação de cada uma delas. As informações foram adquiridas por meio dos sites oficiais das Câmaras Municipais, de Portais da Transparência, do Mapa das Câmaras elaborado pelo Tribunal de Contas do Estado de São Paulo e, por fim, de entrevistas feitas com gestores ou responsáveis pelas TVs Câmaras ${ }^{4}$. Assim, um primeiro ponto a observar é a realidade local diversificada em que se encontram estes veículos, refletida nas diferenças de números de habitantes e orçamento do Poder Legislativo municipal:

Tabela 1 - TVs Câmaras municipais no interior do estado de São Paulo

\begin{tabular}{lllll}
\hline Cidade & Habitantes & $\begin{array}{l}\text { Orçamento }{ }^{5} \text { do } \\
\text { Poder Legislativo } \\
\text { (em reais) }\end{array}$ & $\begin{array}{l}\text { Canal na rede } \\
\text { aberta de } \\
\text { televisão }\end{array}$ & $\begin{array}{l}\text { Ano em que } \\
\text { entrou na Rede } \\
\text { Legislativa de } \\
\text { TV Digital }\end{array}$ \\
\hline Assis & 103.666 & 7.219 .464 & 31.3 & 2013 \\
Barretos & 121.344 & 10.609 .250 & 31.3 & 2012 \\
Bauru & 374.272 & 16.799 .669 & 31.3 & 2013 \\
Botucatu & 144.820 & 4.385 .693 & 61.3 & 2016 \\
Campinas & 1.194 .094 & 101.005 .217 & 39.3 & 2015 \\
Franca & 350.400 & 10.588 .334 & 61.3 & 2018 \\
Jacareí & 231.863 & 21.048 .700 & 39.2 & 2013 \\
Jaú & 148.581 & 6.002 .142 & 34.2 & 2012 \\
Jundiaí & 414.810 & 26.846 .286 & 60.2 & 2016
\end{tabular}

respeito a maior capital do país, com 12.258 milhões de habitantes, o que muda seu perfil de estrutura e alcance. Dessa forma, poderia render, sozinha, outro estudo.

${ }^{4}$ As entrevistas foram feitas por meio de ligação telefônica, enquanto informações adicionais à primeira conversa foram obtidas por meio de WhatsApp e e-mail. Os responsáveis pelas TVs Câmaras entrevistados foram: Márcio Antonio Fabre (Assis), Rafael Luciano de Lucas (Barretos), Marcelo Malacrida (Bauru), Dario DJota Carvalho (Campinas), William Campos Galvão (Franca), Elton Rivas (Jacareí), Ângelo Boaventura (Jaú), Patrícia Montanari Leme (Jundiaí), Amanda Campos (Marília), Rosangela Cavalcante (Mogi das Cruzes), Felipe Marchiori (Piracicaba), Sergio Figueiredo (Ribeirão Preto), Alexandre Gama (São José do Rio Preto), Claudia Cristina de Almeida Jacob (Sorocaba) e Tiago da Costa Pettenuci (Tupã). A exceção está na TV Câmara Botucatu, na qual a autora atua como observadora participante, uma vez que é jornalista concursada do veículo.

${ }^{5}$ Período de referência: setembro de 2018 a agosto de 2019, em levantamento feito pelo Tribunal de Contas do estado de São Paulo. 


\begin{tabular}{lllll} 
Marília & 237.130 & 12.356 .664 & 31.2 & 2014 \\
Mogi das Cruzes & 440.769 & 29.235 .187 & 60.2 & 2015 \\
Piracicaba & 400.949 & 32.541 .826 & 60.4 & 2013 \\
Ribeirão Preto & 694.534 & 48.323 .916 & 31.4 & 2012 \\
São José do Rio Preto & 456.245 & 21.433 .809 & 28.2 & 2015 \\
Sorocaba & 671.186 & 48.924 .404 & 31.3 & 2015 \\
Tupã & 65.477 & 6.136 .767 & 34.3 & 2013 \\
\hline
\end{tabular}

Fonte: VIEIRA, 2019.

Por mais que todas as cidades se encontrem no interior de um mesmo estado, as diferenças locais são expressivas, tanto entre municípios, quanto entre o Poder Legislativo municipal. Neste cenário, TVs Câmaras estão presentes em apenas uma cidade de pequeno porte (até 100 mil habitantes), se concentram em sua maioria em doze cidades de médio porte (de 100 a 500 mil habitantes) e ainda aparecem em três cidades de grande porte (acima de 500 mil habitantes), sendo uma delas Campinas, que ultrapassa a marca de um milhão de moradores. De maneira esperada, portes municipais diferentes exigem estruturas legislativas diferentes, reverberando também no orçamento anual de cada Câmara. Uma vez que os custos de investimento e manutenção das TVs Câmaras estão diretamente ligados ao orçamento da Casa Legislativa, este valor pode trazer reflexos significativos em quais possibilidades de trabalho possuem e como se organizam as emissoras. Do menor orçamento anual - Botucatu, com pouco mais de $\mathrm{R} \$ 4$ milhões - ao maior - Campinas, com mais de $\mathrm{R} \$ 100$ milhões - passando por uma média de R 23 milhões, percebese que são números distintos não só entre si, mas também bastante mais humildes quando comparados às esferas federais e estaduais. A Lei Orçamentária Anual de 2019 previa para a Câmara dos Deputados, por exemplo, um orçamento aproximado de $\mathrm{R} \$ 6,3$ bilhões (BRASIL, 2020); já a Assembleia Legislativa do Estado de São Paulo, a mais cara do país, custa cerca de 1,3 bilhão por ano (QUINTELLA; CHAPOLA, 2019). Ao mesmo tempo em que o fato pode gerar um ambiente local baseado na pluralidade de experiências, focado na criatividade e na eficiência, há uma série de dificuldades que podem surgir para o funcionamento das emissoras, assim como no cumprimento pleno de suas funções e obrigações legais, principalmente se estas forem discutidas levando em consideração somente "os grandes" do setor, ou seja, as emissoras federais seguidas das estaduais.

Ainda sobre estes primeiros dados, nota-se que todas as emissoras estão no ar por meio da multiprogramação. Por exemplo, em Botucatu, temos a TV Câmara dos Deputados no canal 61, a TV ALESP no 61.2, a TV Senado no canal 61.4 e finalmente a TV Câmara Botucatu no 61.3, todas utilizando um mesmo transmissor, o que era a proposta da Rede Legislativa desde o 
A nova dinâmica local na comunicação legislativa: um olhar sobre o perfil das TVs Câmaras municipais do interior do estado de São Paulo

princípio. As emissoras também começaram a entrar no ar logo após a criação da Rede Legislativa, em 2012, com Barretos, Jaú e Ribeirão Preto iniciando seus trabalhos na televisão aberta no mesmo ano. Franca, inaugurada em 2018, foi a última a entrar para a lista. Vale destacar que, embora algumas emissoras de fato tenham começado suas atividades com a consignação do canal por meio da Rede Legislativa, outras já funcionavam na televisão a cabo há muito tempo, somente adaptando sua estrutura para transmissão do sinal nesta outra modalidade. É o caso da TV Câmara Bauru, uma das pioneiras do setor, completando 22 anos de existência em 2020.

Estabelecido quem são as TVs Câmaras municipais no interior do estado de São Paulo e a diversidade de suas realidades locais, agora aprofundamos o olhar sobre como estas diferenças elementares refletem na estrutura e organização de cada uma delas. Este olhar é importante principalmente para desenvolvimentos futuros destes dados, pois, como já observou Sant'Anna ao comparar critérios editoriais de emissoras legislativas municipais, estaduais e federais, "quanto mais fragilizado era o vínculo empregatício de um trabalhador, por exemplo, um comissionado ou um terceirizado, menos independente era a postura com que esse profissional, por si próprio, se colocava diante da notícia" (SANT'ANNA, 2019, p. 17).

Seguindo a tendência de autonomia entre cada emissora e cada Poder Legislativo, na municipalidade a opção por modelos de gestão distintos continua. Enquanto sete TVs Câmaras possuem indicados políticos ocupando um cargo comissionado na gestão, outras seis contam com servidores efetivos na mesma posição. É importante ressaltar que ocupar o cargo por meio de indicação política não significa não ter formação técnica ou acadêmica específica da área, no caso, de comunicação; a questão aqui está em avaliar como a pessoa chegou ao cargo e não sua qualificação para ocupá-lo. Dessa forma, as emissoras foram assim classificadas:

Tabela 2 - modelo de organização - gestão

\begin{tabular}{llll}
\hline $\begin{array}{l}\text { Gestor comissionado } \\
\text { (indicação) }\end{array}$ & $\begin{array}{l}\text { Gestor efetivo (cargo de } \\
\text { carreira ou função } \\
\text { gratificada) }\end{array}$ & Sem gestão definida \\
\hline Cidades & Campinas & Assis & Botucatu \\
& Jaú & Barretos & Franca \\
& Marília & Bauru & Jundiaí \\
& Mogi das Cruzes & Jacareí & \\
& Piracicaba & Ribeirão Preto & \\
& Sorocaba & São José do Rio Preto & \\
& Tupã & & $\mathbf{3}$ \\
\hline Total & $\mathbf{7}$ & $\mathbf{6}$ & \\
\hline
\end{tabular}

Fonte: VIEIRA, 2019. 
Interessante notar que, além de optar por diferentes modelos, as treze Câmaras com gestão definida nomearam os cargos responsáveis pelas suas emissoras de maneira totalmente nãopadronizada, revelando mais um indicador de autonomia e pluralidade/não-unidade entre si. Foram encontradas as denominações: diretor de TV Câmara, diretor de comunicação (três), diretor de mídia, diretor de comunicação social, diretor de TV legislativa, assessor de comunicação com atribuições de diretor, secretário-diretor de comunicação, coordenador de TV e rádio Câmara, coordenador de comunicação, coordenador de TV Câmara, e secretário legislativo de comunicação.

A pluralidade / não-unidade da Rede também se encontra nas discrepâncias com as quais cada emissora lida com sua opção de modelo de gestão. Temos o exemplo de Tupã e Bauru. Além do secretário legislativo de comunicação na gestão de forma indicada, Tupã conta com um vereador designado como coordenador da TV Câmara, com papel inclusive de autorizar ou não pautas sugeridas. Já em um caminho contrário, Bauru firmou em legislação municipal (Lei Municipal 6043, de $1^{\circ}$ de abril de 2011) que é preciso ser jornalista ou radialista concursado na área de comunicação para ocupar cargo de diretor de comunicação. Ainda em Jacareí, embora não haja legislação, é regra interna que comissionados só são permitidos em gabinetes de vereador ou presidente.

As outras três TVs Câmaras que ainda não possuem (ou momentaneamente não possuem) gestão definida demonstram que as emissoras legislativas municipais estão em processo de formação ou, muitas vezes, por falta de normativas, sofrem com inseguranças estruturais. Em Botucatu, quem responde pela TV Câmara é a diretora administrativa da Câmara. Em Franca, um oficial legislativo do setor de compras encarregado da aquisição dos equipamentos iniciais da emissora acabou se tornando o responsável pelo canal. Embora seja concursado, não tem nenhuma função gratificada para exercer o papel - em suas palavras, a incumbência "caiu no meu colo". Em Jundiaí, uma assessora de comunicação que atua na TV responde informalmente por ela, em um processo na qual uma parceria entre TV Câmara Jundiaí e TVTEC Jundiaí se desfez, modificando bastante a dinâmica existente até então.

Enquanto a presença de comissionados ou concursados na gestão demonstra certo equilíbrio entre ambas as opções, quando falamos em equipe técnica, já encontramos um predomínio da escolha por um corpo de servidores concursados sobre terceirizados, como listado a seguir: 
Quadro 1 - modelo de organização - equipe técnica

\begin{tabular}{llll}
\hline & Concursados & Terceirizados & $\begin{array}{l}\text { Misto (concursados e } \\
\text { terceirizados) }\end{array}$ \\
\hline Cidades & Assis & Campinas & $\begin{array}{l}\text { Barretos } \\
\text { Jacareí }\end{array}$ \\
& Bauru & Franca & \\
& Botucatu & Mogi das Cruzes & \\
& Jaú & & \\
& Jundiaí & & \\
& Marília & & \\
& Piracicaba & & \\
& Ribeirão Preto & & \\
& São José do Rio Preto & & $\mathbf{2}$ \\
& Sorocaba & & \\
Tupã & $\mathbf{3}$ & \\
\hline Total & $\mathbf{1 1}$ & & \\
\hline
\end{tabular}

Fonte: VIEIRA, 2019.

Pode-se inferir que uma gestão política não espelha em todo um corpo de servidores na mesma situação, uma vez que, constitucionalmente - no artigo 37, inciso V (BRASIL, 1988) sequer existe a possibilidade de comissionados exercerem funções técnicas, cabendo aqui ressaltar a atuação do TCE-SP, que fiscaliza e faz recomendações acerca das atribuições que podem ser designadas a cargos de confiança. Das dezesseis TVs Câmaras estudadas, onze optaram por ter em seu quadro técnico apenas concursados, três contam com terceirizados e duas possuem um modelo misto, com concursados e terceirizados.

Neste ponto, cabe uma nota sobre a estrutura na qual se encontra o corpo técnico destas emissoras que, mais uma vez, pode variar consideravelmente. Enquanto a TV Câmara Campinas, a mais encorpada de todas, chega a dispor de aproximadamente 33 funcionários terceirizados, seguida de Jacareí, com 24, e São José do Rio Preto, com 23 (que ainda são números modestos em uma estrutura organizacional de emissora televisiva), a maioria das outras TVs trabalham com um pessoal total que varia de quatro a dez servidores. É o caso de Assis e Jundiaí, com quatro pessoas, Botucatu, com cinco, Tupã, Barretos, Jaú e Piracicaba, com sete, oito, oito e nove, respectivamente. Bauru e Marília contabilizam onze funcionários, Sorocaba dezessete e Ribeirão Preto dezoito. O quadro de funcionários da TV Câmara de Franca, por exemplo, embora esteja classificado como modelo terceirizado, na verdade se resume a um gestor ("oficial legislativo") e a um terceirizado responsável pela operação técnica dos aparelhos usados nas transmissões ao vivo. Outro ponto relevante é que muitas dessas equipes, já relativamente reduzidas, possuem entre suas atribuições não somente o funcionamento da TV Câmara, mas também da comunicação 
geral da Casa Legislativa, o que inclui responder por sites, redes sociais e assessoria de imprensa, além de Rádio Câmara quando existe. Incluem-se nesta dinâmica, total ou parcialmente, as TVs Câmaras de Assis, Barretos, Bauru, Botucatu, Jacareí, Jaú, Jundiaí, Marília, Ribeirão Preto, São José do Rio Preto e Sorocaba.

Embora o artigo não se aprofunde nesta organização, cabe ao menos visualizar a realidade na qual a comunicação legislativa municipal se encontra para compreender melhor, finalmente, $o$ que chega ao cidadão, ou seja, o que é produzido por cada emissora e forma sua programação. Barros e Lemos (2019) já haviam observado, em estudo sobre a TV Câmara dos Deputados, que a emissora legislativa trabalhava sua grade de programas utilizando quatro estratégias principais: transmissão ao vivo das sessões legislativas; divulgação de informações políticas por meio de telejornais; debates e entrevistas; e programas históricos, culturais e documentários, sempre equilibrados entre as expectativas do público, dos parlamentares e dos produtores envolvidos em um jogo de forças no qual a visibilidade política é uma das principais cartas na mesa. Na realidade local, não se nota nada muito longe disso. Assim, os modelos de produção encontrados nas TVs Câmaras observadas aqui foram divididos em três categorias, expostas na tabela abaixo:

Quadro 2 - modelos de produção

\begin{tabular}{llll}
\hline Transmissões ao vivo do & $\begin{array}{l}\text { Transmissões ao vivo do } \\
\text { plenário e conteúdo } \\
\text { legislativo }\end{array}$ & $\begin{array}{l}\text { Transmissões ao vivo do } \\
\text { plenário, conteúdo } \\
\text { legislativo e conteúdo não- } \\
\text { legislativo }\end{array}$ \\
\hline Cidades & Barretos & Assis & Bauru \\
& Franca & Jundiaí & Botucatu \\
& Mogi das Cruzes & Campinas \\
& Ribeirão Preto & Jacareí \\
& & Jaú \\
& & Marília \\
& & Piracicaba \\
& & São José do Rio Preto \\
& & Sorocaba \\
& & Tupã \\
\hline \multirow{2}{*}{ Total } & 4 & $\mathbf{1 0}$ \\
\hline
\end{tabular}

Fonte: VIEIRA, 2019.

A razão de ser das emissoras legislativas é possibilitar maior transparência ao Poder Legislativo e visibilidade ao trabalho parlamentar, contribuindo, tangencialmente, à educação para cidadania. Está em seu cerne de atuação a transmissão ao vivo de atividades realizadas em plenário, como já estipulado pela Lei do Cabodifusão. No interior do estado de São Paulo, todas 
as TVs Câmaras cumprem este papel central. No entanto, a maioria delas ultrapassa esta obrigação primária e produz conteúdo legislativo (aqui considerado o que diz respeito à cobertura da rotina da Casa Legislativa, como eventos, atuação de comissões, atividades parlamentares, acontecimentos institucionais, etc., seja por meio de telejornal fixo ou não, além de qualquer tipo de material que pretenda aproximar e elucidar o universo legislativo ao cidadão ou conte com a participação de parlamentares) e até mesmo conteúdo não-legislativo (aqui considerado o que diz respeito a assuntos sem relação direta com o que acontece no Poder Legislativo, por exemplo, informativos gerais sobre fatos da cidade, programas de entrevistas e debates sem parlamentares, documentários e reportagens especiais, quadros educativos, culturais ou com focos diversos, como meio ambiente, direitos, saúde, juventude, inclusão, entre outros). Algumas TVs definem bem o seu rol de atuação, por exemplo, a TV Câmara Jacareí, que, segundo seu gestor, afirma estar alicerceada no tripé utilidade pública, divulgação da atividade parlamentar e prestação de serviços. Por outro lado, outras emissoras ainda se restringem às transmissões ao vivo do plenário, preenchendo o restante da programação com retransmissão da ALESP ou material de terceiros ${ }^{6}$. Cabe dizer que nem sempre a opção por expandir a atuação a conteúdo não-legislativo tem ligação com uma estrutura maior de produção, já que algumas das TVs Câmaras com menor equipe produzem material deste tipo, enquanto outras maiores optam por focar somente nas transmissões, o que nos faz inferir estarem envolvidas na questão não só dificuldades operacionais, mas também uma falta de clareza do propósito e potencialidades de uma emissora legislativa.

\section{Considerações Finais}

Embora devam cumprir as mesmas funções - em especial de transparência e prestação de contas do parlamento - que as já mais consolidadas TVs Legislativas do âmbito federal e estadual, quando olhamos de perto a estrutura e a organização das suas "irmãs" legislativas do âmbito municipal, percebemos que elas pouco têm a ver com as grandes emissoras. Características singulares geram situações também peculiares a este ambiente local: por um lado, dificuldades organizacionais são constantes, por exemplo, oriundas de quadro pessoal enxuto ou do desafio de se produzir programação em tempo integral; por outro lado, existe a eventual chance das limitações propiciarem um espaço localizado de inovação, eficiência, criatividade, pluralidade e integração com a realidade municipal, tornando o cidadão mais próximo de todo o processo legislativo e também televisivo e comunicacional. Qual destas duas facetas é a preponderante é um assunto a ser discutido em outros trabalhos.

O não conhecimento sobre este cenário diferenciado ainda gera certos riscos. Na falta de

\footnotetext{
${ }^{6}$ Importante ressaltar o papel da ASTRAL (Associação das TVs e Rádios Legislativas) na união e no apoio às emissoras locais. Por meio de compartilhamento de conteúdo em nuvem, ela possibilita troca de material entre os associados e preenchimento de grade de programação. Hoje, das dezesseis TVs Câmaras municipais estudadas, dez são associadas à ASTRAL.
} 
normatizações ou maior atenção ao setor, há a possibilidade de surgirem discrepâncias além da pluralidade saudável entre os níveis federais, estaduais e municipais, que confundam a percepção do papel primordial da comunicação pública exercida pelas emissoras legislativas e, ainda mais grave, que envolvam barreiras para o cumprimento de obrigações legais. É o caso quando se demanda mais produção ou investimentos - um exemplo recente são os decorrentes de exigências para recursos de acessibilidade - de Poderes Legislativos locais que contam com orçamentos absurdamente menores que os Poderes de outras esferas.

A comunicação legislativa que surge e se transforma, com um inédito e talvez inesperado protagonismo do cenário local, exige um olhar mais sensível a estas emissoras e seus respectivos espaços de atuação, que podem ser, afinal, os responsáveis por um novo paradigma para uma comunicação legislativa cidadã e pela expansão do acesso da sociedade à rotina dos parlamentos federais, estaduais e municipais não só no interior do estado de São Paulo, mas por todo o país.

\section{Referências}

BARROS, Antonio Teixeira de, et al. História dos canais de comunicação do Legislativo. In: V Congresso Nacional de História da Mídia. 2007, São Paulo. Anais... São Paulo: Intercom, 2007, p. 1 - 12. Acesso em: 12 mai. 2021.

BARROS, Antonio Teixeira de; LEMOS, Cláudia Regina Fonseca. Parlamento midiático: análise da programação da TV Câmara do Brasil sob a ótica dos parlamentares, dos mediamakers e do público. Observatório (OBS*) Journal, v. 13, p. 107-130. 2019. Acesso em: 12 ma. 2021.

BAURU. Lei Municipal 6043, de $1^{\circ}$ de abril de 2011. Reestrutura o cargo de diretor de comunicação da Câmara Municipal de Bauru e suas respectivas atribuições. Bauru, SP: Câmara municipal, 2011.

BRASIL. Câmara dos Deputados. Assessoria de Imprensa - Orçamento. Brasília, 2020. Disponível em: https://www2.camara.leg.br/comunicacao/assessoria-de-imprensa/orcamento. Acesso em 27 fev. 2020.

BRASIL. Câmara dos Deputados. Rede Legislativa de Rádio e TV. Brasília, 2020. Disponível em: https://www2.camara.leg.br/comunicacao/rede-legislativa-radio-tv. Acesso em: $27 \mathrm{de} \mathrm{fev.}$ 2020.

BRASIL. [Constituição (1988)]. Constituição da República Federativa do Brasil. Brasília, DF: Senado Federal, 1988.

BRASIL. Lei n ${ }^{\circ}$ 8977, de 6 de janeiro de 1995. Dispõe sobre o serviço de TV a cabo e dá outras providências. Brasília, DF: Câmara dos Deputados, 1995.

BUCCI, Eugenio. O Estado de Narciso: A comunicação pública a serviço da vaidade particular. São Paulo: Companhia das Letras, 2015.

BUCCI, Eugênio; FIORINI, Ana Maria; CHIARETTI, Marco. Indicadores de Qualidade nas Emissoras Públicas: Uma Avaliação Contemporânea. Brasília: Unesco, 2012.

CARVALHO, Mariana Martins de. Comunicação pública: função e legitimação das tevês legislativas federais. 2014. 313 f. Tese (Doutorado em Comunicação) — Faculdade de Comunicação, Programa de Pós-Graduação em Comunicação, Universidade de Brasília, Brasília, 2014. Disponível em: https://repositorio.unb.br/handle/10482/15921. Acesso em: 12 mai. 2021. 
LEMOS, Cláudia Regina Fonseca; BERNARDES, Cristiane Brum; BARROS, Antonio Teixeira de. TV Câmara, TV pública? As TVs legislativas brasileiras na transição para a plataforma digital. Observatorio (OBS*) Journal, vol. 5, nº 2, 2011. Disponível em: http://obs.obercom.pt/index.php/obs/article/view/482 . Acesso em: 12 mai. 2021.

MATOS, Heloíza. A comunicação pública no Brasil e na França: desafios conceituais. In: XXXII Congresso Brasileiro de Ciências da Comunicação, 2009, Curitiba. Anais Intercom 2009. Curitiba: Intercom, 2009. Disponível em: http://www.intercom.org.br/papers/nacionais/2009/resumos/R4-3060-1.pdf. Acesso em: $1^{\circ}$ mar. 2020.

MATOS, Heloíza. Comunicação pública, democracia e cidadania: o caso do Legislativo. Revista Líbero. São Paulo v. 2, n. 3-4, 1999. Disponível em: http://www.portcom.intercom.org.br/pdfs/783e6552ae7775c83c58acadcbd0563e.PDF . Acesso em: 12 mai. 2021.

PAULINO, Fernando Oliveira. As TVs Legislativas como instrumento de promoção e diversidade e pluralismo. E-legis, n. 29, p. 21-28, maio/ago. Brasília, 2019. Disponível em: http://e-legis.camara.leg.br/cefor/index.php/e-legis/article/view/502 . Acesso em: 12 mai. 2021.

PERUZZO, Cicilia M. Krohling. Mídia regional e local: aspectos conceituais e tendências. Comunicação \& Sociedade. São Bernardo do Campo, a. 26, n. 43, p. 67-84, 1. sem. 2005.

QUINTELLA, Sérgio; CHAPOLA, Ricardo. As mordomias da Assembleia Legislativa, que custa 1,3 bilhão por ano. Veja São Paulo, 31 mai. 2019. Disponível em:

https://vejasp.abril.com.br/cidades/raio-x-assembleia-sp-capa/. Acesso em: 27 fev. 2020.

RENAUlT, Letícia. Comunicação e Política nos Canais de Televisão do Poder Legislativo no Brasil. Belo Horizonte: ALMG, 2004.

SANT'ANNA, Francisco. A experiência da TV Senado e o desafio das emissoras legislativas no Brasil. E-legis, n. 29, p. 15-20, maio/ago. Brasília, 2019. Disponível em: http://elegis.camara.leg.br/cefor/index.php/e-legis/article/view/503. Acesso em: 12 mai. 2021.

VIEIRA, M. C. S. R.. TVs Legislativas no Brasil: histórico, regulação e perspectiva. $42^{\circ}$ CONGRESSO BRASILEIRO DE CIÊNCIAS DA COMUNICAÇÃ̃O, 2019, Belém (PA). Anais do $42^{\circ}$ Congresso Brasileiro de Ciências da Comunicação, 2 a 7 de setembro de 2019. São Paulo: INTERCOM, 2019. p. 1-14.

Artigo submetido em: 2021-03-02

Artigo reapresentado em: 2021-03-26

Artigo aceito em: 2021-04-19 